\title{
MODELOS DE FINANCIACIÓN DE VIVIENDA. CASOS: MÉXICO, CHILE Y COLOMBIA
}

\author{
Miguel David Rojas López* \\ Nelson Yovany Bran Rueda** \\ Carolina Rincón López ${ }^{* * *}$
}

Recibido: 02/08/2012

Aceptado: 07/05/2013

\section{RESUMEN}

Esta investigación compara los sistemas de financiación de vivienda en Chile, Colombia y México. Usando metodologías similares en la amortización se observa que las variables principales en los créditos son el interés, el monto y plazo. El índice de precio al consumidor -IPC-, varía en cada país, porque realizan el cálculo de forma diferente y este afecta la unidad de cuenta empleada para la amortización de los créditos de vivienda.

Palabras clave: financiación de vivienda, hipotecas, IPC, unidad de cuenta.

Ph. D en Ingeniería Universidad Nacional de Colombia. E-mail: mdrojas@unal.edu.co

Ingeniero Administrador Universidad Nacional de Colombia. E-mail: nybranr@unal.edu.co

*** Ingeniería de Sistemas e Informática Universidad Nacional de Colombia. E-mail:carinconlo@unal.edu.co 


\title{
MORTGAGE FINANCING MODEL FOR HOUSING. CASE: MEXICO, CHILE AND COLOMBIA
}

\begin{abstract}
This research article presents a brief comparison of housing finance systems in Chile, Colombia and Mexico. By using similar amortization methodologies, it was observed that the principal credit variables are the interest, the amount and the timelapse. The Consumer Price Index- CPI, which varies in every country, is calculated differently and therefore it affects the unit of account applied for the amortization of housing credits.
\end{abstract}

Key words: Housing systems, mortgage, CPI, unit of account. 


\section{INTRODUCCIÓN}

La financiación de vivienda está reglamentada por normas que afectan el mercado inmobiliario. Un modelo de financiación de vivienda acorde con las necesidades propias de cada país es estudiado y comparado con otros modelos para realizar analogías que permitan mejorar este en cada región.

La información es obtenida de entidades públicas y privadas de diferentes países por medio de la web, haciendo comparaciones entre intereses, valores y plazos de financiación para comparar los sistemas hipotecarios.

\section{MARCOTEÓRICO}

La vivienda es para los hogares el mayor gasto y el activo más importante. La financiación de vivienda es el componente del buen funcionamiento de sistema de vivienda; los estudios internacionales existentes sobre financiación de vivienda son informativos, pero carecen del análisis formal y están centrados en pocos países [1].

\subsection{Oferta y demanda}

La financiación de vivienda se rige por factores de oferta y demanda [1].

Según el Banco Mundial (1993), entre los diferentes países, la oferta de vivienda tiende a ser idiosincrásica.

En contraste, la demanda en todos los países es relativamente predecible, ya que varía con el nivel de ingresos. Para un determinado nivel, la disponibilidad de financiamiento hipotecario varía con las tasas de interés [1].

\subsubsection{Demanda}

La demanda de financiación de vivienda depende del porcentaje del crecimiento de hogares y el ingreso de cada uno de ellos.

El valor de la cuota de vivienda está en función de los ingresos mensuales, y la vivienda, para ser asequible, requiere amortización de pagos a largo de plazo; para Colombia, generalmente es a 15 años [1].

\subsubsection{Oferta}

Se requiere una política que promueva el préstamo a largo plazo, la habilidad para valorar la propiedad y la información sobre la solvencia de los potenciales prestatarios; las variables macroeconómicas como la inflación son factores que promueven la movilización de fondos como ahorros y depósitos a la vista, mercados de capital, incentivos gubernamentales o mercados secundarios [1].

Como se observa en la tabla 1 , los créditos hipotecarios son homogéneos respecto a plazos; en lo referente al porcentaje de financiación pre-

Tabla 1: Financiación de vivienda en algunos países

\begin{tabular}{|l|c|c|l|}
\hline \multicolumn{1}{|c|}{ País } & Años & $\begin{array}{c}\text { Financiación } \\
(\%)\end{array}$ & \multicolumn{1}{|c|}{ Tipo de interés } \\
\hline Alemania & $20-30$ & 80 & Fijo \\
\hline Australia & 25 & $90-100$ & Variable(Fijo) \\
\hline Brasil & 20 & $75-100$ & Variable \\
\hline Canadá & 25 & $75-95$ & Fijo/Variable \\
\hline Chile & $8-20$ & 70 & Variable \\
\hline China & $10-30$ & 80 & Variable \\
\hline Colombia & 30 & 70 & Variable \\
\hline España & $15-20$ & 100 & Variable \\
\hline Francia & $15-20$ & 100 & $\begin{array}{l}\text { Mayoritariamente } \\
\text { fijos/elección }\end{array}$ \\
\hline India & 20 & 85 & Mixto \\
\hline México & 20 & $80-100$ & Variable \\
\hline Malasia & 30 & 80 & Variable \\
\hline Países Bajos & 30 & 125 & Fijo(Mixto) \\
\hline Portugal & $25-30$ & 90 & Variable \\
\hline Reino Unido & 25 & 110 & Variable \\
\hline Estados Unidos & 30 & 100 & Fijo (Mixto) \\
\hline Venezuela & 20 & $70-75$ & Variable \\
\hline
\end{tabular}

Fuente: Warnock, 2008 
dominan rangos similares, a excepción del Reino Unido y los Países Bajos donde el porcentaje de financiación es superior al valor de la vivienda; se observan tasas variables para los créditos en la mayoría de los países.

\subsubsection{El mercado}

La profundidad del mercado hipotecario se presenta por medio del saldo de créditos vigentes y el Producto Interno Bruto (PIB) [2]. Se puede clasificar como:

Mercado primario: aquí se encuentra todo el conjunto de créditos con garantía hipotecaria que las entidades financieras conceden para compra y rehabilitación de vivienda; los créditos otorgados están relacionados con los sistemas de financiación de las entidades crediticias. La captación de fondos en el mercado primario tiene tres formas de recaudar que son depósitos, ahorro vinculado o emisión de títulos hipotecarios [2].

Mercado secundario: en este se efectúan operaciones de compra y venta de hipotecas y títulos hipotecarios, dotando al mercado primario de liquidez. Además, estandariza los mercados locales [2, 3].

La tabla 2 muestra la proporción entre el PIB y la ponderación de cuánto representa en el crédi-

Tabla 2: Profundidad financiera de crédito hipotecario

\begin{tabular}{|l|c|c|}
\hline \multicolumn{1}{|c|}{ País (año) } & PIB (\%) & Crédito total (\%) \\
\hline Argentina (2001) & 4 & 15 \\
\hline Bolivia (2001) & 8,6 & 16,3 \\
\hline Chile (2001) & 10,8 & 17,7 \\
\hline Colombia (2001) & 7 & 25 \\
\hline Panamá (2002) & 24,4 & 26,4 \\
\hline Perú (2001) & 2,9 & 9,5 \\
\hline México & 2,1 & 13,5 \\
\hline Estados Unidos & 79,6 & 87,2 \\
\hline Unión Europea & 42,6 & 41 \\
\hline
\end{tabular}

Fuente: Banco Interamericano de Desarrollo, 2005 to. En esta variable el mercado hipotecario refleja cómo el sistema crediticio de vivienda impulsa la economía de un país; por ejemplo, en USA, el 79,6\% del PIB es soportado por el 87,2\% del crédito hipotecario. Lo contrario ocurre en otros países como Argentina que solo el 4\% del PIB es soportado por el 15\% del crédito.

\section{FINANCIACIÓN DEVIVIENDA EN COLOMBIA}

Los sistemas utilizados para créditos están denominados en pesos o en Unidad de Valor Real, UVR [4]. Los sistemas de financiación de vivienda en UVR son los más usuales para las familias de ingresos bajos y medios [12].

\subsection{Sistema de cuota constante en UVR}

Consiste en cuotas mensuales fijas en UVR durante todo el crédito y se ajusta por inflación; la cuota mensual crece en pesos. Se amortiza a capital desde el inicio del crédito, y el saldo del crédito en UVR disminuye mes a mes [4].

\subsection{Sistema de amortización constante a capital en UVR}

Este sistema resulta de dividir el valor total del crédito en UVR por el número de meses. A la cuota resultante se suman los intereses causados sobre el saldo del crédito para cada período. En este sistema la cuota mensual disminuye en UVR pero aumenta en pesos por efecto de la inflación, a una tasa inferior al índice de precios al consumidor -IPC- [4].

\subsection{Sistema de cuota decreciente mensualmente en UVR}

En este sistema las cuotas del crédito en UVR disminuyen mensualmente y suben nuevamente al cabo de 12 meses. Para cada período anual del crédito se repite la serie de doce cuotas decrecientes. El decremento anual equivalente debe ser igual a la 
inflación proyectada y no podrá modificarse dentro del plazo. Este sistema busca establecer una cuota en pesos que permanece casi constante durante un año y tiene un crecimiento igual a la inflación para el siguiente [4].

\subsection{Sistema de cuota constante en pesos}

Es un sistema en el que la cuota mensual es fija en pesos por todo el plazo del crédito. En este sistema las cuotas no varían durante la obligación [4].

\subsection{Sistema de amortización constante a capital}

Sistema en que la cuota mensual resulta de dividir el capital por el número de meses pactado, más los intereses calculados sobre el saldo insoluto. Bajo este sistema, las cuotas mensuales son decrecientes [4].

\subsection{Comparación de amortizaciones}

Un sistema de amortización se compone de los siguientes elementos:

- La función que define el comportamiento de las cuotas.

- La ecuación para el cálculo de la primera cuota que permite el cálculo de las demás.

- La tabla de amortización.

El saldo del crédito se puede conocer en todo momento por la ecuación de recurrencia (1) [5].

$S_{k}=S_{k-1}\left(1+i_{12}\right)-\gamma_{k}$

De donde:

$K=1,2, \ldots, 12 \mathrm{n}$

$S_{0}=$ Valor del crédito

$S_{12 n}=0$

Para construir la ecuación (1), el saldo del crédito en el mes $\mathrm{k}\left(\mathrm{S}_{k}\right)$, es igual al saldo del período anterior $\left(S_{k-1}\right)$ más los intereses generados por el saldo, menos la cuota abonada.
$S_{k}=S_{k-1}+i_{12} S_{k-1}-\gamma_{k}$

También se conoce el valor de la primera cuota, porque de esta dependen las demás. Se calcula el valor presente iterando la ecuación (2) y luego se despeja el valor de la cuota.

$$
\left.S_{12 n}=\left(1+i_{12}\right)^{12 n} \mid S_{0}-\sum_{j=1}^{12 n} \gamma_{j}\left(1+i_{12}\right)^{-j}\right\rceil
$$

Multiplicando a ambos lados de la ecuación (3) por $v_{12}^{12 n}$ se tiene:

$S_{12 n} v_{12}^{12 n}=S_{0}-\sum_{j=1}^{12 n} v_{12}^{j} \gamma_{j}$

Como la condición de cierre al final del crédito es $S_{12 n}=0$ entonces:

$$
S_{0}=\sum_{j=1}^{12 n} v_{12}^{j} \gamma_{j}
$$

Lo que indica que el valor presente del crédito es igual a la suma de los valores presentes de las cuotas.

La forma que tome la función $\gamma_{k}$ define el sistema de amortización [5].

Datos de simulación: Crédito de 50 millones, interés del 11\%, plazo de 10 años y UVR de $\$ 167.9940$ para el día 28-06-2009. La figura 1 muestra cómo el saldo decrece rápidamente cuando es un crédito por abono fijo a capital en pesos. La figura 2, los intereses son más bajos desde el comienzo del crédito y decrecen rápidamente en la amortización por abono a capital en UVR.

\section{CASO DEVIVIENDA EN CHILE}

En Chile el sistema tradicional para adquirir vivienda es el crédito hipotecario mediante las Letras de Crédito Hipotecario -LCH-. En segundo lugar se encuentra el Mutuo Hipotecario Endosable MHE- y, finalmente, el leasing habitacional. Estas tres alternativas financian prácticamente el $80 \%$ de las viviendas [6]. 
Se usan las Unidades de Fomento -UF-, como una unidad de cuenta o moneda teórica, que varía diariamente según las fluctuaciones del IPC del mes anterior.
En Chile se trabaja en tres factores clave: inflación, política social de vivienda por parte del Estado y el desarrollo del mercado de capitales [7].

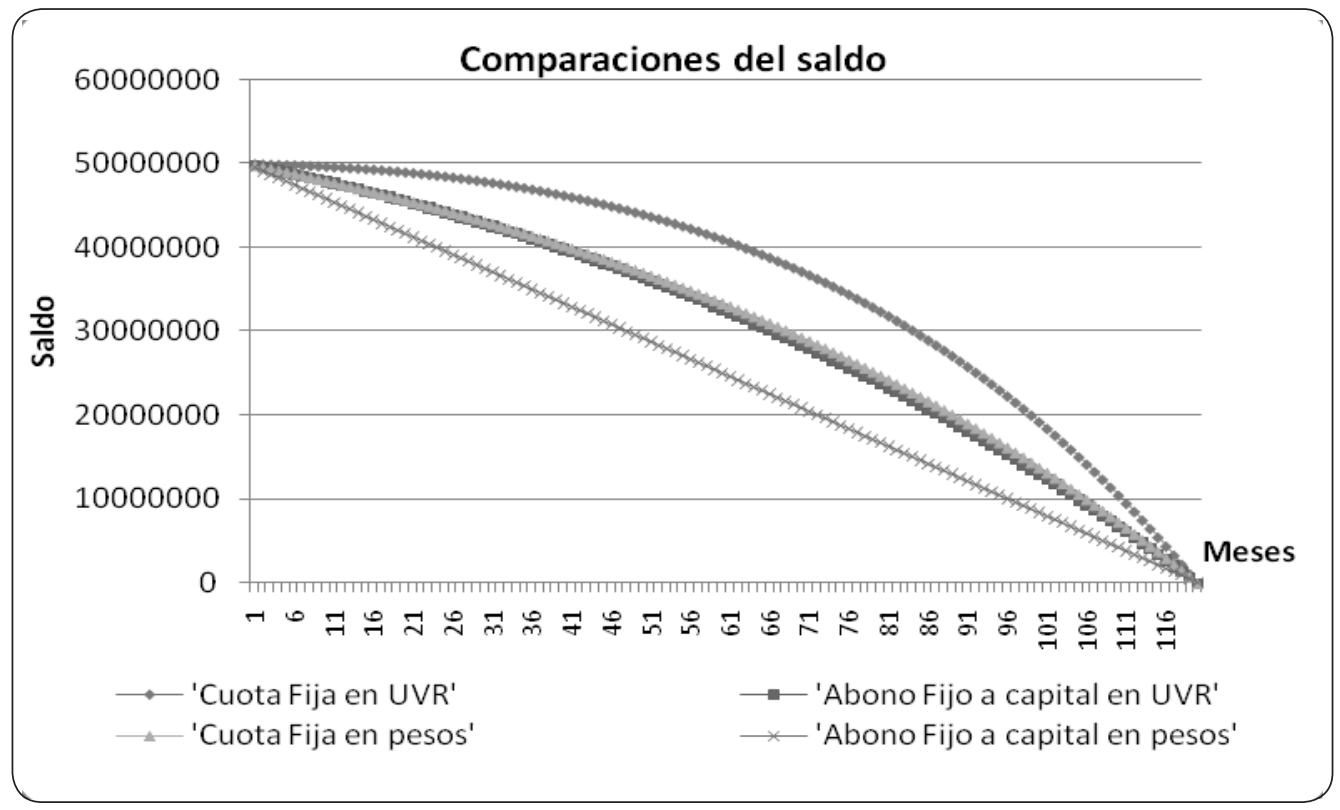

Figura 1: Comparación de saldos por 4 sistemas de amortización Fuente: elaboración propia

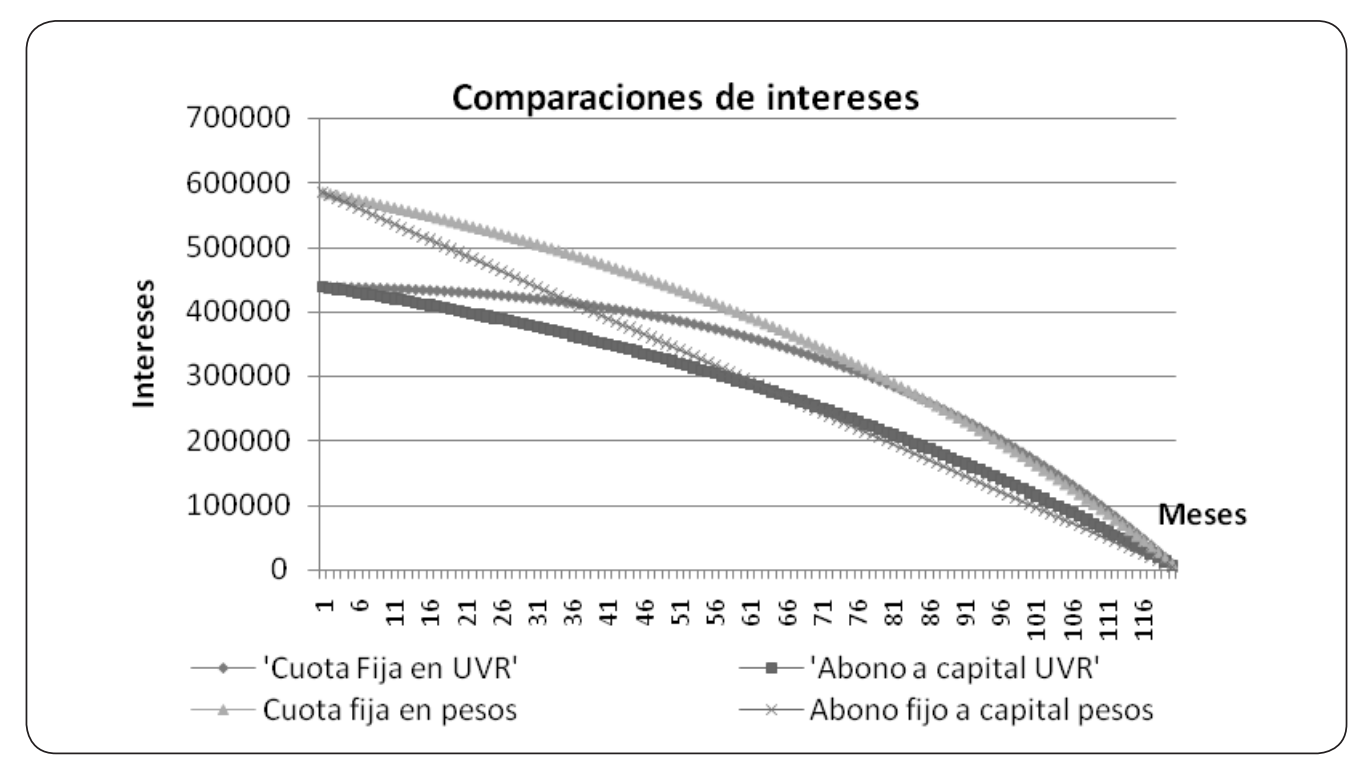

Figura 2: Comparación de intereses por 4 sistemas de amortización Fuente: elaboración propia 


\subsection{Financiación por letras hipotecarias}

Fundamentado en el instrumento financiero emitido al portador, este se recupera con el pago de cupones periódicos, generalmente trimestrales, y comprende cuotas de amortización y de intereses. La letra es emitida por un banco solo con motivo del otorgamiento del préstamo que debe estar garantizado con el inmueble [7].

El monto máximo del crédito no debe ser superior al $75 \%$ del valor de tasación de la propiedad ofrecida en garantía y, en general, al calificar a los potenciales deudores, los bancos consideran como capacidad de pago una fracción no superior a 25\% de los ingresos mensuales familiares [7].

El riesgo vinculado con la emisión de estos instrumentos está asociado con la morosidad del conjunto de deudores que respaldan una serie de letras, dado que los dividendos asociados con el préstamo hipotecario proporcionan los recursos financieros que requiere el banco para respaldar los cupones; la garantía está asumida principalmente por el banco y luego por los deudores; por ello las letras se consideran instrumentos titularizados. Se otorgan a un plazo de 15 a 20 años, generalmente en pesos y a una tasa de interés que oscila entre $6 \%$ у $9 \%$ [7].

\subsection{Financiación por mutuos hipotecarios}

El mutuo es un préstamo en dinero, es decir, que el deudor obtiene directamente del acreedor el dinero con que pagará al vendedor de la propiedad que está adquiriendo.

Los mutuos pueden ser otorgados por bancos, sociedades financieras y agentes administradores de mutuos hipotecarios endosables. El agente o el banco otorgan el contrato, mediante endoso, a una compañía de seguros o a otras sociedades autorizadas para invertir en estos instrumentos, con el objeto de refinanciar la operación y continuar otorgando créditos [7].

La tabla 3 presenta las características del sistema de amortización en Chile.

A diferencia del sistema de letras de crédito hipotecarias, en el mutuo hipotecario endosable el contrato es el que se constituye en instrumento financiero. La cesión se realiza descontando el flujo de dividendos a que se ha comprometido el deudor, a la tasa interna de retorno que se acuerde con el inversionista institucional, más una prima por riesgo. Dicha tasa de cesión es inferior a la de colocación del mutuo, lo que permite al otorgante obtener su margen de utilidad. En consecuencia, en el uso de los mutuos hipotecarios no existe una

Tabla 3: Sistema en Chile

\begin{tabular}{|c|c|c|}
\hline Condiciones & Letra de crédito & Mutuo endosable \\
\hline Otorgamiento y administración & Bancos & Bancos y Agentes administradores de mutuos hipotecarios \\
\hline Plazo & $1-30$ años & $1-30$ años \\
\hline Monto máximo & $75 \%$ & $80 \%$ \\
\hline Tasa de interés & Fija o variable, mas una comisión & Fija o variable sin recargo de comisión \\
\hline Moneda & Unidad de Fomento (UF) & Unidad de Fomento (UF) o en pesos \\
\hline Dividendos & Mensuales, iguales, sucesivos y vencidos & Mensuales, iguales y sucesivos \\
\hline Periodo de gracia & No hay & Máximo 3 meses \\
\hline Amortización extraordinaria & Total o parcial según el contrato & Total o parcial según el contrato \\
\hline Garantía & El inmueble & El inmueble \\
\hline Seguro incendio & Sí & Sí \\
\hline Desgravamen & Sí & Sí \\
\hline
\end{tabular}

Fuente: elaboración propia 
comisión explícita propiamente dicha. De esto se deduce que en el mutuo el riesgo del instrumento está directamente relacionado con la solvencia del deudor y la calidad de la garantía [7].

En la figura 3 se muestra una simulación para un crédito en letras por valor de 60 millones de pesos colombianos equivalente a $\$ 15,505.238$ pesos chilenos, con interés del $11 \%$, a un plazo de 10 años, con una UF de 20956,09 para el día 21 de junio del 2009. El saldo y los intereses presentan el mismo comportamiento de decrecimiento para un crédito hipotecario en letras.

\section{CASO DEVIVIENDA EN MÉXICO}

Desde 1995, se establecieron créditos en unidades de inversión -UDI- en México. Las UDI son la unidad de cuenta que refleja el cambio en los precios al consumidor. Los créditos en UDI pueden ser en tasa fija y pagos en UDI o tasa fija y pagadera en salarios [8]. El plazo de los créditos en UDI es máximo 25 años en pesos, UDI o salarios mínimos.
Para realizar las proyecciones se usan los parámetros salario mínimo en el Distrito Federal SMDF- y $n$ veces el Salario Mínimo Mensual en el Distrito Federal, VSMMDF. En la tabla 4 se muestran las diferentes hipotecas y sus características.

\subsection{Consideraciones sobre los sistemas de amor- tización en México}

En la financiación por créditos en pesos, las hipotecas se prestan en condiciones de tasa de interés y pago en pesos. En ellos se conoce por anticipado el pago [8].

Existen otros créditos otorgados por la entidad financiera estatal o privada como: INFONAVIT, SOFOL, banco o ISSSTE [8].

\subsection{Enganche o anticipo}

Es "el porcentaje máximo de financiamiento"; el beneficiario debe disponer de dinero para iniciar el negocio. Es el anticipo, y entre sus modalidades más frecuentes es el enganche diferido, integración

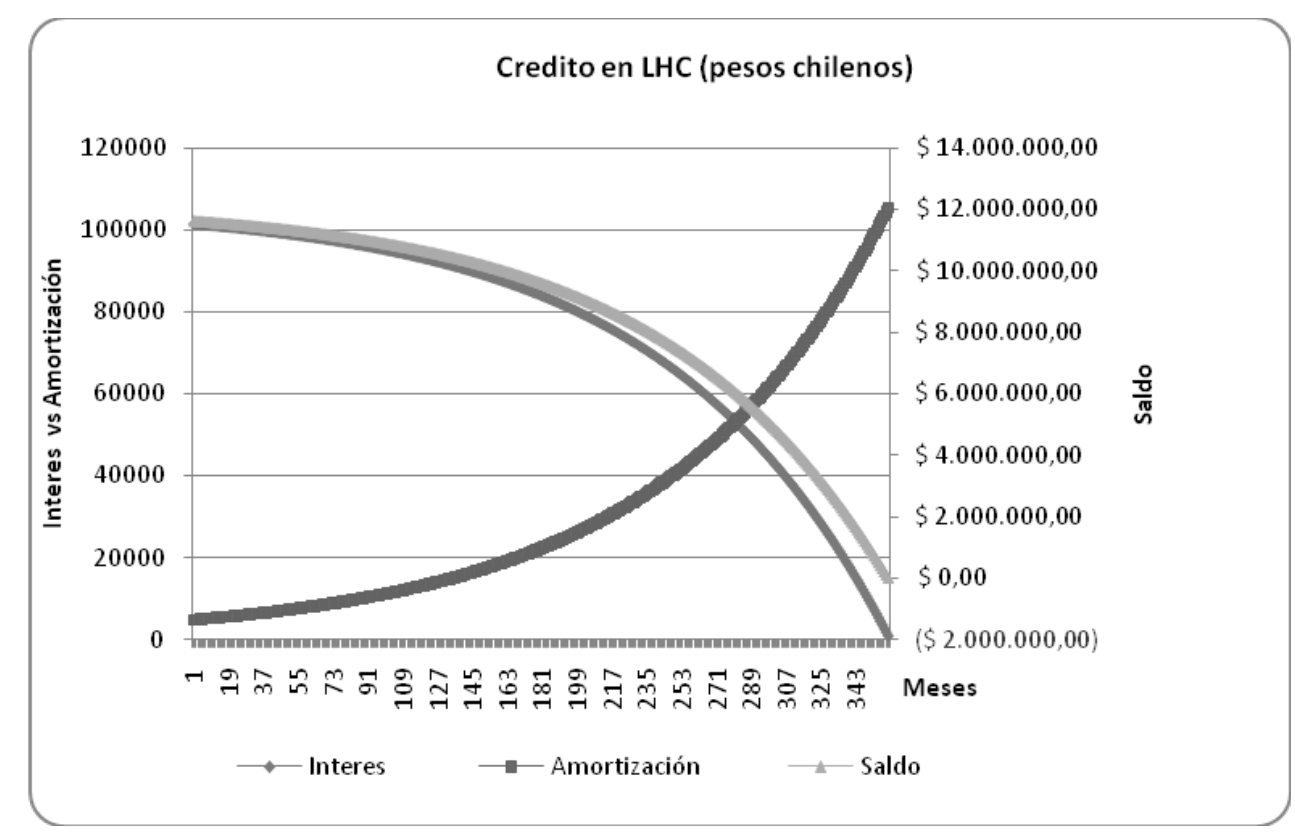

Figura 3: Amortización de un crédito en Letras hipotecarias

Fuente: elaboración propia 
gradual a través de ahorro o entrega al contado en una sola exhibición [8].

La porción que pertenece al usuario del crédito se obtiene restando el capital insoluto de la deuda al préstamo original y a esto se le suma el enganche [8].

\subsection{Costo anual total -CAT-}

Anualiza la totalidad de los costos directos inherentes al crédito. El CAT de un crédito en pesos no se compara con el otro nombrado en UDI; el CAT de una tasa se refiere a la fórmula financiera que difiere de la tasa de interés del crédito, y que resulta alta por considerar los costos financieros del crédito adicionales a la tasa de interés [9]. En la simulación valor del préstamo en UDI es de 90393, con valor de la UDI 4.247,856 para el 22 de junio del 2009, valor de enganche del 10\% del saldo, con tasa fija anual del $7.45 \%$ en UDI y del $11.94 \%$ en pesos (MXN). Las figuras 4 y 5 muestran como el abono a capital difiere de manera apreciable entre un crédito en UDI y un crédito en pesos desde el primer mes.

\section{METODOLOGÍA}

\subsection{Comparación de los modelos de financiación}

Se usan las amortizaciones en pesos, ya que son los sistemas "menos afectados" por las unidades de cuenta UVR, UF o UDI y que presentan más similitud para realizar análisis comparativos.

En la tabla 5 se observa el cálculo de las unidades de cuenta; el referente es el IPC el cual tiene ponderaciones y distribuciones distintas para cada uno los tres países en mención: Chile, México y Colombia.

Los elementos presentados en la tabla 5 muestran como las estructuras para el ofrecimiento de crédito hipotecario de los diferentes países presentan grandes diferencias; por ejemplo, en el caso del cálculo del IPC, en Chile se basa en 483 productos y 157 artículos [10], mientras que en Colombia son 371 que están en fase de revisión actualmente de-

Tabla 4. Hipotecas en México

\begin{tabular}{|c|l|}
\hline Hipotecas & \multicolumn{1}{c|}{ Características } \\
\hline En UDI con tasa fija & $\begin{array}{l}\text { La tasa de interés no varía durante el plazo del crédito, el pago no varía en UDI y se conoce cuántas } \\
\text { cuotas se pagarán mensualmente por el crédito. Las UDI se convierten a pesos el día del pago y éste } \\
\text { se liquida en pesos [8]. }\end{array}$ \\
\hline En UDI con tasa fija y pago en & $\begin{array}{l}\text { La tasa de interés no varía durante el plazo del crédito, sin embargo el pago se efectúa en términosdel } \\
\text { salario mínimo del Distrito Federal. Al inicio del crédito el pago se expresa en salarios mínimos [8]. }\end{array}$ \\
\hline \multirow{2}{*}{ A tasa de interés fija en pesos } & $\begin{array}{l}\text { La tasa de interés se define en el contrato y no cambia durante el tiempo que dure la hipoteca. Se } \\
\text { paga la misma mensualidad y se conoce el pago y el plazo, independiente que las tasas de interés de } \\
\text { mercado varien. Existe una comisión por pago anticipado [8]. }\end{array}$ \\
\hline A interés variable en pesos & $\begin{array}{l}\text { Durante un periodo en meses se aplica una tasa de interés definida y durante el plazo, la tasa de } \\
\text { interés que se aplica varía según las condiciones del mercado. Para determinar estas fluctuaciones se } \\
\text { aplica el índice de referencia que puede añadir o restar un porcentaje fijo, llamado diferencial. Esto } \\
\text { hace que los pagos disminuyan cuando las tasas de interés bajan pero que se incrementen si las tasas } \\
\text { suben [8]. }\end{array}$ \\
\hline A interés mixto en pesos & $\begin{array}{l}\text { Combina periodos de dos o más años cuando permanece fijo el interés y un periodo a interés varia- } \\
\text { ble. Se dice que la tasa de interés no cambia pero los pagos crecen a una tasa definida por lo que se } \\
\text { considera como mixta [8]. }\end{array}$ \\
\hline
\end{tabular}

Fuente: elaboración propia 
Tabla 5: Analogías y diferencias de los países estudiados

\begin{tabular}{|l|c|c|c|}
\hline \multicolumn{1}{|c|}{ Elemento- PAIS } & Chile & Colombia & México \\
\hline Unidad de Cuenta & UF & UVR & UDI \\
\hline $\begin{array}{l}\text { Fórmula de cálculo de la unidad } \\
\text { de cuenta }\end{array}$ & $\begin{array}{c}R_{d}=\left(1+\frac{I P C_{-1}}{100}\right)^{1 / d} \\
U F_{\text {dia }}=U F_{\text {dia-1 }} \times R_{d}\end{array}$ & $U V R_{t}=U V R_{15} \times(1+i)^{t / d}$ & \\
\hline Base cálculo de la unidad & IPC & IPC & IPC \\
\hline Instituto que avala el IPC & INE & DANE & INEGI \\
\hline Plazos (Años) & $1-30$ & $1-30$ & $1-30$ (Pesos) - UDI \\
$(1-25)$
\end{tabular}

Fuente: elaboración propia

bido al cambio de base al año 2008 [11]; se suman, además, las ponderaciones que se les otorgan a los diferentes productos de la canasta familiar en cada país; en las clasificaciones por área geográfica, por área urbana, entre otras, este indicador ejerce un efecto importante al momento de comparar los créditos hipotecarios.

La simulación muestra la conversión a pesos colombianos, así se comparan en la misma moneda, para el supuesto son: $\$ 60^{\prime} 000.000$, con plazo de 10 años, una tasa promedio del 11\% bajo amortizaciones en pesos usadas en los tres países. En las figuras 6 y 7, México es la mejor opción en financiación de vivienda;, el saldo, intereses y aportes a capital muestra menores costos, la ventaja es por el enganche del 10\% del valor y en la tabla de amortización mejora la deuda.

En las figuras $8 \mathrm{~A}$ y $8 \mathrm{~B}$ para México, sin el valor de enganche, el mejor sistema de financiación de vivienda es Chile, como se aprecia en la curva de interés.

\section{CONCLUSIONES}

Los sistemas de amortización son diferentes en cada país, poseen cierta similitud en cuanto a metodologías de cálculo, aplicabilidad y relación con otros temas; el IPC juega un papel importante en los modelos de financiación de vivienda, ya que en é se basan las amortizaciones y principalmente los intereses que se generan para el pago de la deuda en el mercado hipotecario.

El porcentaje de tasa de interés para el crédito hipotecario es menor en Chile y México; Colombia es la tasa más alta.

El valor de "enganche" en México permite conseguir una deuda menor al momento de pagar un crédito de vivienda, porque la base del crédito es menor.

Para Chile y Colombia, la amortización, la tasa de interés, periodos y montos son similares, como muestran las proyecciones del crédito hipotecario a futuro.

El sistema de financiación de vivienda se refleja en la proporción del PIB y el porcentaje del crédito 


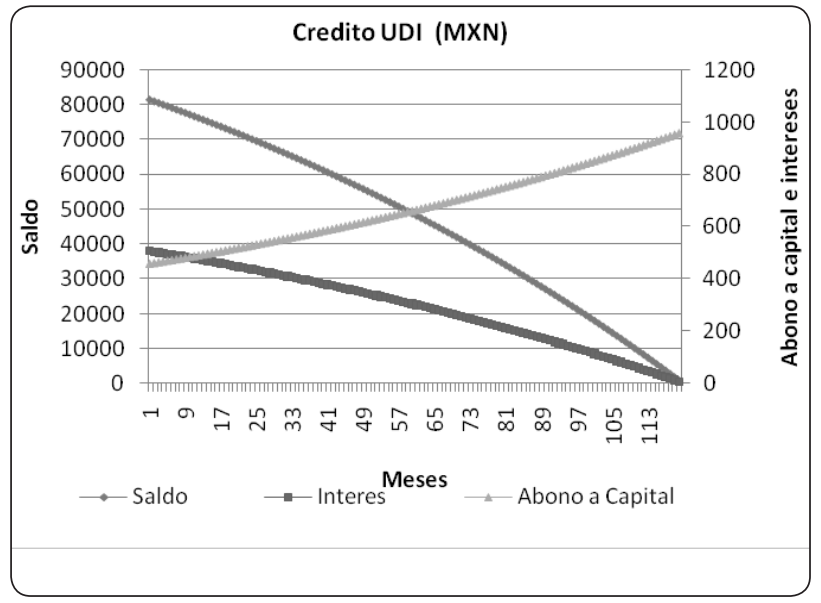

Figura 4: Amortización de deuda en UDI

Fuente: elaboración propia

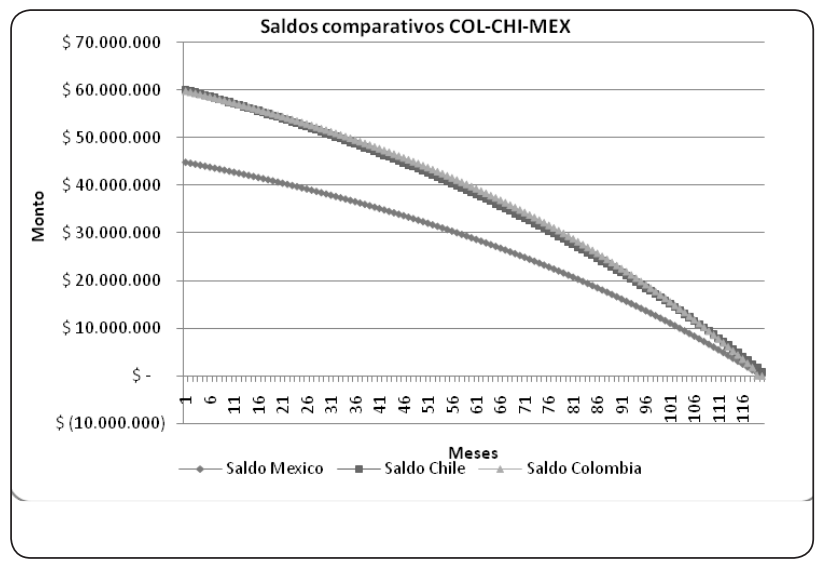

Figura 6: Saldos comparativos

Fuente: elaboración propia

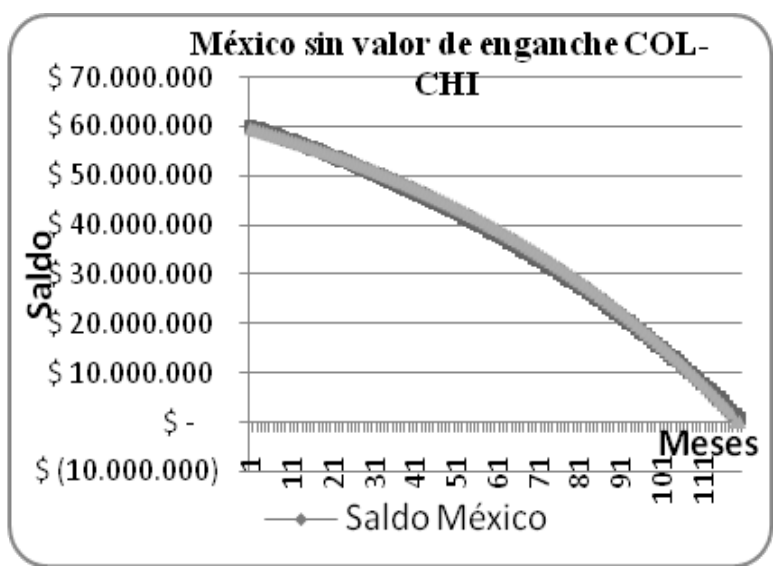

Figura 8a. Saldo sin valor de enganche Fuente: elaboración propia

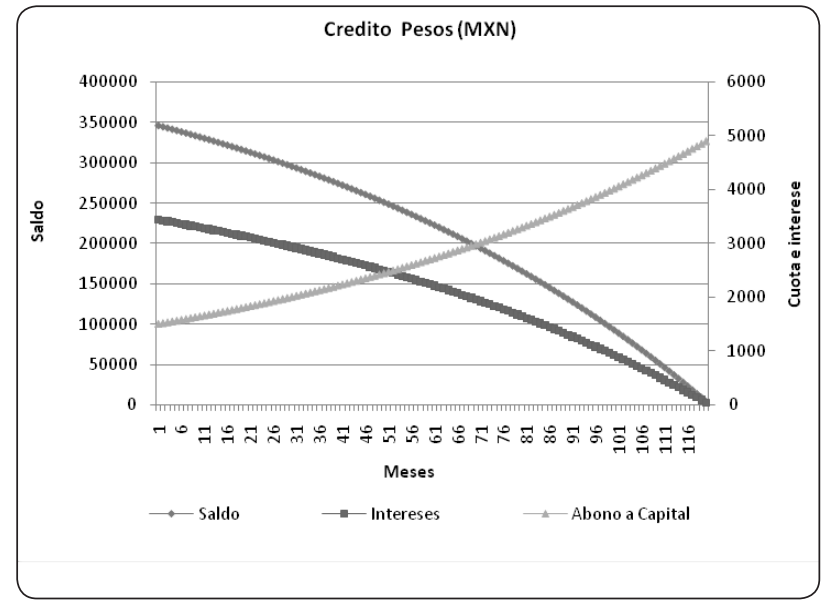

Figura 5: Amortización de deuda en pesos

Fuente: elaboración propia

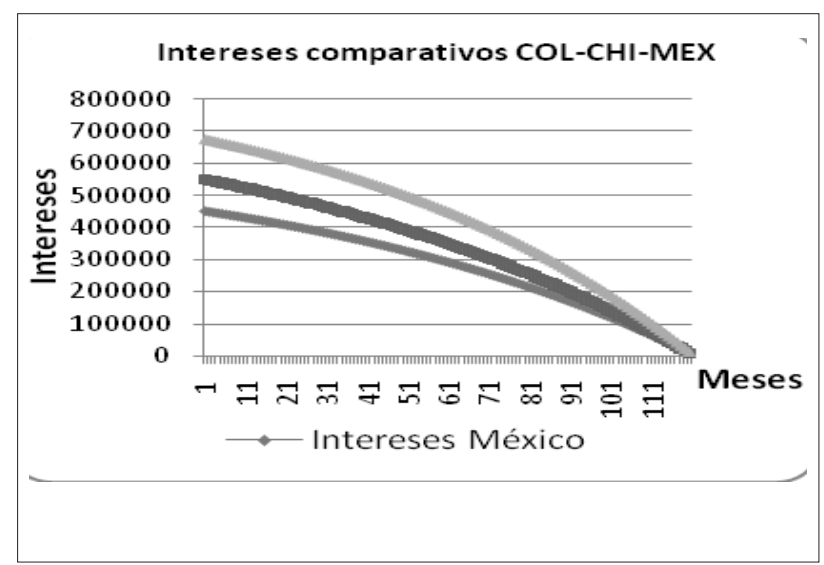

Figura 7: Intereses comparativo

Fuente: elaboración propia

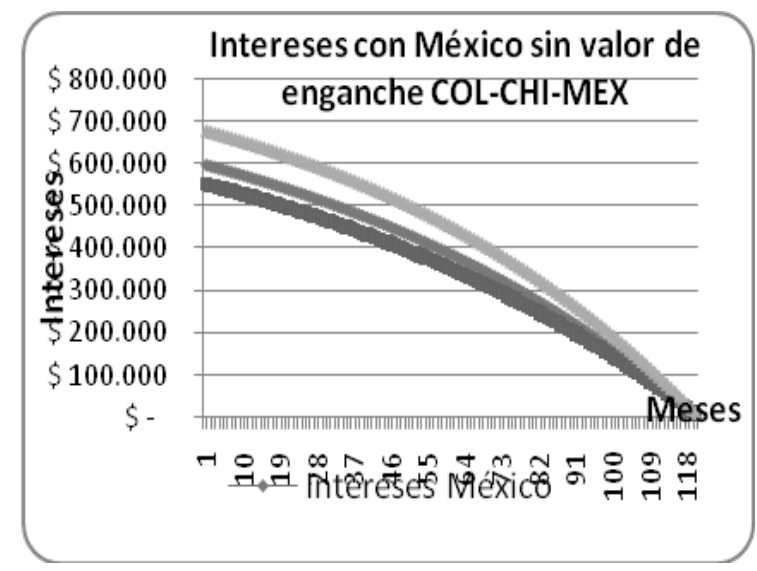

Figura $8 \mathrm{~b}$. Interés sin valor de enganche Fuente: elaboración propia 
hipotecario; esa relación influye en el desarrollo económico de una nación.

El déficit de vivienda es un tema que los países deben afrontar y es importante investigar como incrementar los sistemas de financiación eficiente de vivienda.

\section{REFERENCIAS}

[1] V. Warnock, F. Warnock. Markets and housing finance. Journal of Housing Economics. Number 17 (2008). pág. 239-251. Disponible en: http://dx.doi.org/10.1016/j. jhe.2008.03.001 Consulta: 15 de enero del 2009.

[2] J. Redondo, M. López. El mercado del crédito hipotecario en la Unión Europea. Revista Galena de Economía. Vol. 10, número 001. 2001. Disponible en: http:// redalyc.uaemex.mx/redalyc/pdf/391/39110116.pdf Consulta: 20 de enero del 2009.

[3] Banco Interamericano de Desarrollo. Capitulo 15 - Los cimientos del crédito para la vivienda. 2005. Disponible en: www.iadb.org/res/ipes/2005/docs/Chapter15spa. pdf. Consulta: 30 de noviembre del 2008.

[4] A. Pérez. Financiación de vivienda en Colombia. Mercatura, Revista virtual. Universidad de San Buenaventura. Edición N 7. Medellín. 2006: pp. 12-19. ISSN: 1692-1175 Disponible en: www.usbmed.edu. co/mercatura/nro7/docs/financiacion.doc Consulta: Enero del 2009.
[5] L. Cortés, A. Osorio. Análisis y evaluación de los sistemas de financiación de vivienda en Colombia. 2001. Tesis de grado. Universidad Nacional.

[6] E. Vucina. Valorización, opciones y Spread de letras de crédito hipotecario en Chile. 2004. Universidad Católica de Chile. Disponible en: www.riskamerica.com/ papers/papers.asp?doc $=\mathrm{ValOpSprLCH.pdf}$. Consulta: Marzo 2009

[7] C. García, F. Morandé. Financiación de la vivienda en Chile. Banco interamericano de desarrollo BID. Documento de trabajo $\mathrm{N}^{\circ} 502$. Disponible en: http://idbdocs. iadb.org/wsdocs/getdocument.aspx?docnum=788321. Consulta: 22 de marzo del 2009

[8] SFH. Conoce más sobre los créditos hipotecarios en México. Portal Web. Disponible en: http://www.shf. gob.mx/clientes/2_2_informacion_acreditados.html. Consulta: Marzo 2008.

[9] I. Beteta. Vivienda y Crédito Hipotecario en México. SF. Disponible en: http://www.ibeteta.com/El_CAT_ instrumento\%20.asp. Consulta: Marzo 2009

[10] INE. Disponible en: http://www.ine.cl/canales/chile_estadistico/estadisticas_precios/ipc/metodologia/ pdf/aspectosmetodologicos.pdf. Consulta: marzo 2009.

[11] DANE. Disponible en: http://www.dane.gov.co/files/ investigaciones/fichas/Metodologia_IPC.pdf. Consulta: marzo 2009.

[12] Rojas M., Osorio, A., Jaramillo, M. Sistemas de Financiación de Vivienda. Revista DYNA 132, 65-72. 